\title{
An unusual location of a false cyst of the pancreas about a case (central african republic)
}

\begin{abstract}
Mediastinal pseudocyst is an unusual and rare complication of acute and chronic pancreatitis. The symptoms are nonspecific. Imaging medical is important for diagnosis and treatment.

We present a case of pancreatic mediastinal pseudocyst which is successfully treated bypercutaneous endoscopic drainage. This report is of interest because it describes a rare presentation of a pancreatic pseudo cyst (the first known case in Central Africa republic). It illustrates the range of radiological techniques in management of patients with abdominal pains.
\end{abstract}

Keywords: pseudo cyst; pancreas; médiastinal
Volume 6 Issue 2 - 2017

\author{
BF Kouandongui,' T mobima, ${ }^{2}$ MR Ouaimon ${ }^{3}$ \\ 'Department of Radiology and Medical Imaging of the University \\ Hospital Center Mother Elisabeth DOMITIEN, Africa \\ ${ }^{2} \mathrm{Head}$ of Radiology and Imaging Department of the Friendship \\ Hospital, Africa \\ ${ }^{3}$ Department of Radiology and Medical Imaging of the \\ Friendship Hospital,Africa
}

\begin{abstract}
Correspondence: Kouandongui Bangue Francky, Department of Radiology and Medical Imaging of the University Hospital Center Maman Elisabeth DOMITIEN (CHUMED), Africa, Tel +23675727562/23672384400, Email tmobima5@yahoo.fr
\end{abstract}

Received: October 06, 2016 | Published: February 17, 2017

\section{Introduction}

The natural history of pancreatitis (acute or chronic) is characterized by unpredictable occurrence of several complications including false cysts (pseudocysts) of the pancreas. ${ }^{1}$ The majority of pseudocysts are localized in the pancreas or around the pancreas. Those may also be located at a distance from the case-ci. C'est dufaux pancreatic cyst to médiatisnale location. ${ }^{2}$ This location is rare, its first description in $1951 .^{3}$ It is as serious because of its atypical presentation and complication risks associated with its location ie, mediastinal compression, superinfection and thoraco-pancreatic fistula. ${ }^{4,5}$

We report the first case of a false pancreatic cyst in mediastinal extension known in the Central African Republic which aims to recall this pathology that has an atypical presentation.

\section{Patientet observation}

Mr T.A, aged 46, living in Bangui (Central African Republic) is consulted to emergencies for recurrent epigastric pain and dysphagia lasting for five months in a slimming context. This patient has a history of chronic alcohol abuse. He presented the clinical examination, impaired general condition ( $8 \mathrm{~kg} / 5$ months), a lack of palpable mass in the abdomen. In exploring this pain, abdominal ultrasound showed diffuse punctate calcifications in the entire pancreas, normal pancreatic duct, cystic mass in finely particulate content, lobulated epigastric 103 mmde of major axis in cross section. It rises towards the tail of the pancreas and comes in contact with the heart. This mass was a very individualized wall without color Doppler signal. Chest X-ray showed fluid density mass, homogeneous, regular contours, retro heart (middle mediastinum, lower floor). A Transit oesogastro ulcer (UGI) Additional eliminated the presence of a mega-esophagus, a hiatal hernia or any training in communication with the digestive tract. Faced with increases in serum amylase and urinary amylase, the diagnosis of pancreatic cyst nickname to médiatisnale extension (mediation Lower-middle floor) on chronic pancreatic calcifying stigma was mentioned.

Thoracoabdominal scan is performed to a fine. Elle semiotics revealed a hypo dense formation $(10 \mathrm{UH})$ volume of $400 \mathrm{cc}$, the tail of the pancreas higher growth, reaching the mediastinum where it is in contact with the vena cava lower and the descending aorta. She pushes the stomach and esophagus. Its wall is measured $3.5 \mathrm{~mm}$ and is calcified in places. The pancreas is calcified as a whole. The hypothesis of a false pancreatic cyst of thoracoabdominal seat on chronic pancreatitis was confirmed. The patient underwent drainage of pseudocyst laparoscopically and is out of the hospital at D7. He is fine.

\section{Discussion}

The scientific interest of this observation is that it is above all an exceptional location a false pancreatic cyst. This is the first known case in the Central African Republic (CAR). It raises a question on the systematic exploration of any radiological abdominal pain. She could probably help to reveal the existence of other cases in CAR (Figure 1-5).

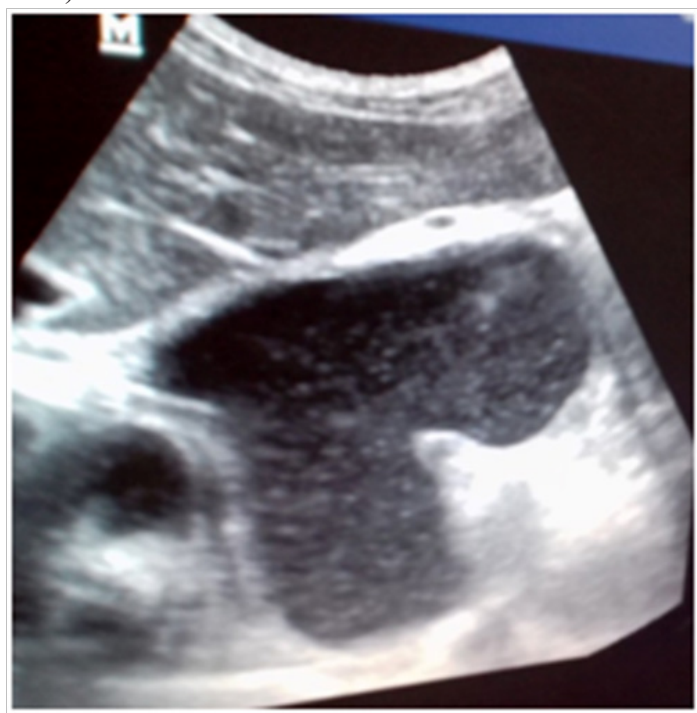

Figure I Echographie abdominale: Presence of a fluid lesion with a clean wall and a fine particulate content in contact with the heart. 


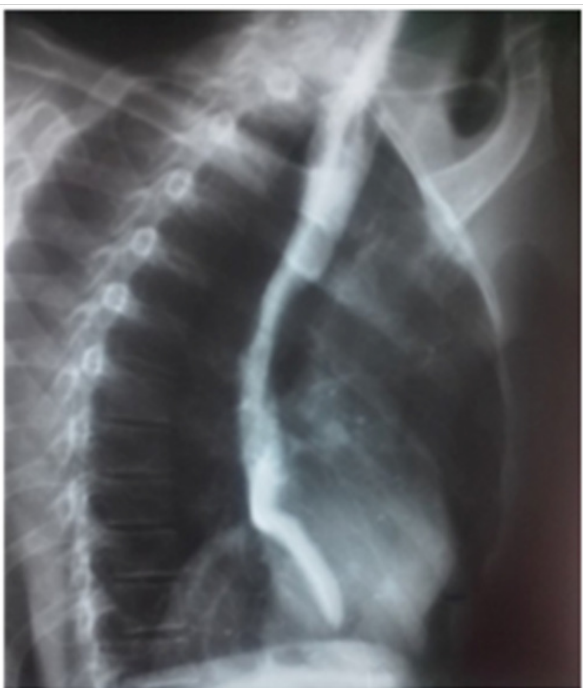

Figure 2 TOGD: Cardiac retro mass with mass effect on the esophageal bottom without communication with it (esophagus).


Figure 3 \& 4 Thoraco-abdominal scanner with injection at arterial time: Presence of a fluid collection beginning at the tail of the pancreas with extension in the thorax. Pancreas completely calcified.

False pancreatic cysts are the main complication of pancreatitis. ${ }^{6}$ They are rich collections of pancreatic enzymes and necrotic tissue, limited by a wall (fibrous capsule) of variable size, location intra- or extra-pancreatic, occurring most often with the waning of a pancreatitis episode known or discovered on pancreatitis chronic calcifying or after pancreatic injury. ${ }^{5-7}$
Mediastinal location of pseudo-cyst is exceptional. It is explained by the leakage of the pancreatic duct necrotic fluid or rupture of a pseudo posterior cyst retro peritoneal space. The migration tendency of the liquid is a common feature. This is readily up, can win the mediastinum through the esophageal or aortic orifice, or by dissecting the diaphragm. ${ }^{9-11}$

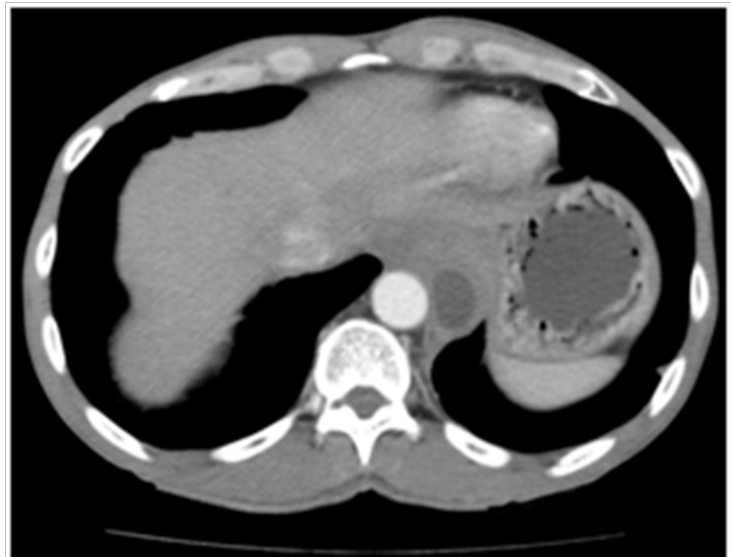

Figure 5 Scanner thoraco-abdominal control: Presence of a pocket residualneonon compressive pseudo-cyst after treatment.

Clinically, no symptoms are not clean. Clinical manifestations are never specific and are difficult to link to a false pancreatic cyst even less mediastinal unusual location. ${ }^{12}$ In our study, it was mainly of epigastric pain, followed by dysphagia and all in a context of weight loss. In the literature, the symptomatology is dominated by signs of compression mediastinal namely epigastric pain, posterior chest pain, dysphagia or dyspnea. The history of the disease, the patient's history (concept of chronic alcoholism), imaging and biology all assemblies are required for the diagnosis. ${ }^{13,14}$

The imagery in this study combined abdominal ultrasound, chest X-ray barium swallow the one hand and the scannerd'autre hand. Abdominal ultrasound revealed the presence of many pseudopancreatic cysts in abdominal location. It is limited in the search for false pancreatic cysts intra thoracic where CT and MRI are more efficient. ${ }^{13,15,16}$ The scanner achieved in this patient confirmed the presence of the false cyst with a finer semiotics and especially its relations with the various neighboring structures (inferior vena cava, descending aorta, left ventricle) unlike abdominal ultrasound, radiography thoracic (front / profile) and the barium swallow.

As for the treatment of pseudo cysts of the mediastinum, it depends on the etiology, cyst size, the number of cysts and complicationsassociées. ${ }^{17}$ In the past, false kystesdu pancreas mediastinal locations were traitéssystématiquement by surgery. Currently the surgical treatment is reserved for forms associated with complications (infection, hemorrhagic transformation, fistula, rupture or compression)..$^{18}$ Now it is possible to drain a pseudocyst of the pancreas mediastinal by non-invasive methods such as drainage percutaneously or endoscopically. ${ }^{19}$ Chez this patient, the drainage laparoscopic surgery has been successfully completed.

\section{Conclusion}

This report describes an exceptional presentation of a false pancreatic cyst through atypical symptoms. It puts highlight the contribution of radiology in the diagnosis and treatment of this disease especially in the exploration of abdominal pain. 


\section{Acknowledgments}

None.

\section{Conflicts of interest}

The authors declare no conflict of interest.

\section{References}

1. Guillaume JC, Desport, P Dolan, D Fressard (1993) Détresse respiratoire aiguë consécutive à un pseudokyste pancréatique médiastinal. Annales Françaises d'Anesthésie et de Réanimatione 12(5): 500-504.

2. Drescher R, Köster O, Lukas C (2008) Mediastinal pancreatic pseudocyst with isolated thoracic symptoms: a case report. J Med Case Rep 2: 180.

3. Topa L, László F, Sahin P, Pozsár J (2006) Endoscopic transgastric drainage of a pancreatic pseudocyst with mediastinal and cervical extensions. Gastrointest Endosc 64(3): 460-463.

4. Bellara I, Allani H, Allani M, MaamriH A (2006) Pseudokyste pancréatique médiastinal fistulisé dans les bronches: a propos d'une observation. Journal de pédiatrie 1548-1549.

5. Balthazar EJ (2002) Acute pancreatitis: assessment of severity with clinical and CT evaluation. Radiology 223(3): 1785-1787.

6. Bødker A, Kjaergaard J, Schmidt A, Tilma A (1981) Pancreatic pseudocysts. Ann surq 194(1): 81-84.

7. Kim YH, Saini S, Sahani D, Hahn PF, Mueller PR, et al. (2005) Imaging diagnosis of cystic pancreatic lesions: pseudocystversus nonpseudocyst. Radiographic 25(3): 671-685.

8. Nguema-mve R, BretonC (1997) A Propos D'un Faux kyste Traumatique Du Pancréas. Médecine d'Afrique Noire 44(1): 54-57.
9. Johnson RH, Owensby LC, Vargas GM, Garcia-Rinaldi R (1986) Pancreatic pseudocyst of the mediastinum. Ann Thorac Surg 41(2): 210212

10. Bhasin DK, Rana SS, Chandail VS, Nanda M, Sinha SK, et al. (2005) Successful resolution of a mediastinal pseudocyst and pancreatic pleural effusion by endoscopic nasopancreatic drainage. JOP 6(4): 359-364.

11. Daehnert W, Schild H, Guenther R, Rothmund M (1983) Computerized tomography of a mediastinal pseudocyst. Eur J Radiol 3(4): 375-377.

12. Faik M, Halhal A, Oudanane M (2000) Les Faux kystes Du Pancréas A propos de 13 Cas. Médecine du Maghreb 79: 25-26

13. Panackel C, Korah AT, Krishnadas D, Vinayakumar KR (2008) Pancreatic Pseudocyst Presenting as Dysphagia: A Case Report. Saudi J Gastroenterol 14(1): 28-30.

14. Jeung MY, Gasser B, Gangi A, Bogorin A, Charneau D, et al. (2002) Imaging of cystic masses of the mediastinum. Radiographics 22(1): 7993.

15. Grace PA, Williamson RC (1993) Modern management of pancreatic pseudocysts. Br J Surg 80(5): 573-581.

16. Prasad BR, Paudel K (2007) A rare case of pancreatic mediastinal pseudocyst. Kathmandu Univ Med J 5(3): 408-411.

17. Aabakken L, Chittom P, Mc Kay DC, Uflacker R, Wilson FA (1997) Percutaneous drainage of a mediastinal pancreatic pseudocyst: A paraspinal, extrapleural CT guided approach. J Vasc Interv Radiol 8(2): 283-285.

18. Rehman S, Jawaid M (2005) Enucleation of pancreatic pseudocyst in a patient suffering from chronic pancreatitis. Pak J Med 21: 380-384. 